Vietnam Journal of Mechanics, VAST, Vol.40, No.3 (2018), pp. $217-232$

DOI: https://doi.org/10.15625/0866-7136/10959

\title{
EFFECTS OF TRANSVERSE NORMAL STRAIN ON BENDING OF LAMINATED COMPOSITE BEAMS
}

\author{
Trung-Kien Nguyen*, Ngoc-Duong Nguyen \\ Ho Chi Minh City University of Technology and Education, Vietnam \\ *E-mail: kiennt@hcmute.edu.vn \\ Received December 07, 2017
}

\begin{abstract}
Effect of transverse normal strain on bending of laminated composite beams is proposed in this paper. A Quasi-3D beam theory which accounts for a higher-order variation of both axial and transverse displacements is used to consider the effects of both transverse shear and normal strains on bending behaviours of laminated composite beams. Ritz method is used to solve characteristic equations in which trigonometric shape functions are proposed. Numerical results for different boundary conditions are presented to compare with those from earlier works, and to investigate the effects of thickness stretching, fibre angles, span-to-height ratio and material anisotropy on the displacement and stresses of laminated composite beams.

Keywords: transverse normal strain, Ritz method, static, laminated composite beams.
\end{abstract}

\section{INTRODUCTION}

Due to the advantages of stiffness-to-weight's ratio and anisotropy material properties, laminated composite (LC) beams have recently attracted a number of researches with different models and approaches. Many beam models with various kinematics have been investigated to predict accurately their static, buckling and vibration behaviours such as layer-wise theories (LWT) [1,2], equivalent single-layer theories (ESLTs) [3-7], zigzag theories (ZZT) [8-10] and Carrera's unified formulation (CUF) [11,12] ... Although the ESLTs have discontinuity of shear stress at the layer interfaces, they are widely used for analysis of isotropic, laminated composite and sandwich beams owing to theirs simplicity in formulation as well as programming [13]. It is noted that the continuity of shear stress at layer interface can also be maintained by using equations of equilibrium of theory of elasticity. Generally, the ESLTs can be classified as classical beam theory (CBT), first-order beam theory (FOBT), higher-order beam theory (HOBT) and Quasi-3D theories. The CBT [14] is only suitable for the analysis of slender beams due to neglecting the shear deformation effects. In order to take into account shear deformation effects, the FOBT [15-18], HOBT [5,19-24] with a higher-order variation of axial displacement,

(C) 2018 Vietnam Academy of Science and Technology 
and Quasi-3D theory [3,25-28] with a higher-order variation of both axial and transverse displacements have been considered for analysis of LC beams.

For numerical approaches, the finite element method is widely used for analysis of static and vibration of LC beams [6,29-38]. For analytical methods, Navier procedure [3] is the simplest one for analysis of LC beams, however this approach is only suitable for simply-supported boundary conditions (BCs). For various BCs, Ritz method has been mostly used by several authors [39-41]. However, the accuracy of this approach depends on the choice of approximate function shapes. A literature survey shows that the number of researches on behaviours of LC beams used the Ritz method are still limited, especially when the effect of transverse normal strain on the bending responses of LC beams is considered. Zenkour [3], Mantari and Canales [7] analysed effects of transverse shear and normal strains on the bending analysis of laminated and sandwich elastic beams using Navier method. Mantari and Yarasca [42] also used Navier method for bending analysis of functionally grade and sandwich beams in which the authors proposed new hybrid-type shear strain shape functions for the in-plane and transverse displacements. The effect of transverse normal strain on the bending responses of LC beams has also been investigated by Mantari and Canales [6] within which a Quasi-3D with 6 degree-offreedom and solved by Hermite-Lagrangian finite element method has been presented. Recently, Vo et al. [38] studied flexural behaviours of LC beams using a four-unknown shear and normal deformation theory, and finite element method.

The objective of this manuscript is to analyse effects of transverse normal strain on the bending responses of LC beams. It is based a Quasi-3D theory which accounts for a higher-order variation of the axial and transverse displacements. The Ritz method is used to solve characteristic equations for various BCs. Numerical results are presented to investigate the effects of transverse normal strain, span-to-height ratio, fibre angle and material anisotropy on the deflections and stresses LC beams.

\section{THEORETICAL FORMULATION}

Consider a LC beam with rectangular section $b \times h$ and length $L$ as shown in Fig. 1 . It is made of $n$ plies of orthotropic materials in different fibre angles with respect to the $x$-axis.

\subsection{Kinetic, strain and stress relations}

The displacement field of LC beams based on [3] is expressed by

$$
\begin{gathered}
u(x, z)=u_{0}(x)+z u_{1}(x)-\frac{1}{2} z^{2} w_{1, x}(x)+z^{3}\left[-\frac{4}{3 h^{2}}\left(w_{0, x}(x)+u_{1}(x)\right)-\frac{1}{3} w_{2, x}(x)\right], \\
w(x, z)=w_{0}(x)+z w_{1}(x)+z^{2} w_{2}(x)
\end{gathered}
$$

where $u_{0}$ and $w_{0}$ are the axial and transverse displacements of mid-plan of the beam, respectively; $u_{1}$ is the rotation of a transverse normal about the $y$-axis; $w_{1}$ and $w_{2}$ are additional higher-order terms. The comma indicates a partial differentiation with respect to the corresponding subscript coordinate. It is worth to noticing that if the stretching 


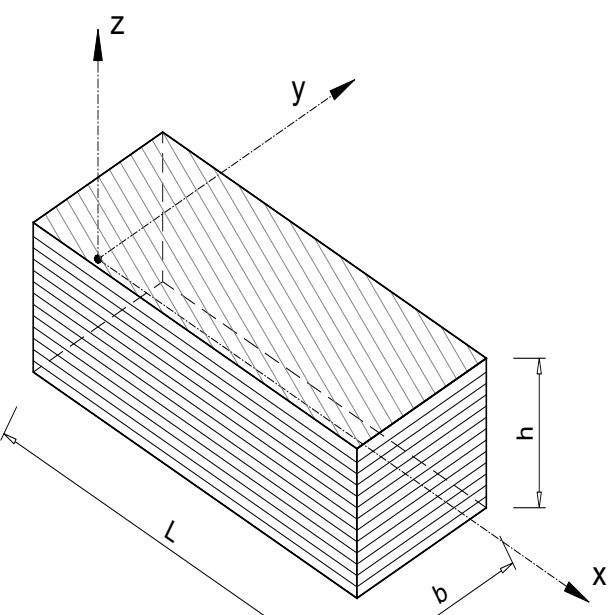

Fig. 1. Geometry and coordinate of a LC beam

strain is ignored ( $w_{1}$ and $w_{2}$ are omitted) in Eq. (1), the present displacement field will become to Reddy's HOBT [43]

$$
\begin{gathered}
u(x, z)=u_{0}(x)+z u_{1}(x)-\frac{4 z^{3}}{3 h^{2}}\left(w_{0, x}(x)+u_{1}(x)\right), \\
w(x, z)=w_{0}(x),
\end{gathered}
$$

The non-zero strains of the beams are derived from Eq. (1) as follows

$$
\begin{gathered}
\varepsilon_{x}=\varepsilon_{x}^{(0)}+z \varepsilon_{x}^{(1)}+z^{2} \varepsilon_{x}^{(2)}+z^{3} \varepsilon_{x}^{(3)}, \\
\varepsilon_{z}=\varepsilon_{z}^{(0)}+z \varepsilon_{z}^{(1)} \\
\gamma_{x z}=\gamma_{x z}^{(0)}+z^{2} \gamma_{x z}^{(1)}
\end{gathered}
$$

where

$$
\begin{gathered}
\varepsilon_{x}^{(0)}=u_{0, x}, \quad \varepsilon_{x}^{(1)}=u_{1, x}, \quad \varepsilon_{x}^{(2)}=-\frac{1}{2} w_{1, x x}, \varepsilon_{x}^{(3)}=-\frac{4}{3 h^{2}}\left(w_{0, x x}+u_{1, x}\right)-\frac{1}{3} w_{2, x x}, \\
\varepsilon_{z}^{(0)}=w_{1}, \varepsilon_{z}^{(1)}=2 w_{2}, \gamma_{x z}^{(0)}=u_{1}+w_{0, x}, \gamma_{x z}^{(1)}=-\frac{4}{h^{2}}\left(u_{1}+w_{0, x}\right),
\end{gathered}
$$

The elastic strain and stress relation of $k^{\text {th }}$-layer in global coordinate is given by

$$
\left\{\begin{array}{l}
\sigma_{x} \\
\sigma_{y} \\
\sigma_{z} \\
\sigma_{y z} \\
\sigma_{x z} \\
\sigma_{x y}
\end{array}\right\}^{(k)}=\left(\begin{array}{cccccc}
\bar{C}_{11} & \bar{C}_{12} & \bar{C}_{13} & 0 & 0 & \bar{C}_{16} \\
\bar{C}_{12} & \bar{C}_{22} & \bar{C}_{23} & 0 & 0 & \bar{C}_{26} \\
\bar{C}_{13} & \bar{C}_{23} & \bar{C}_{33} & 0 & 0 & \bar{C}_{36} \\
0 & 0 & 0 & \bar{C}_{44} & \bar{C}_{45} & 0 \\
0 & 0 & 0 & \bar{C}_{45} & \bar{C}_{55} & 0 \\
\bar{C}_{16} & \bar{C}_{26} & \bar{C}_{36} & 0 & 0 & \bar{C}_{66}
\end{array}\right)^{(k)}\left\{\begin{array}{c}
\varepsilon_{x} \\
\varepsilon_{y} \\
\varepsilon_{z} \\
\gamma_{y z} \\
\gamma_{x z} \\
\gamma_{x y}
\end{array}\right\},
$$


where the $\bar{C}_{i j}$ are transformed elastic coefficients (see [43] for detail). For a laminated beam of small width in the $y$-direction, the stresses $\sigma_{y}, \sigma_{x y}$ and $\sigma_{y z}$ can be neglected because it is so narrow that these stresses are unlikely to grow up to a degree of significance [27]. By setting $\sigma_{y}=\sigma_{x y}=\sigma_{y z}=0$, Eq. (5) is reduced to

$$
\left\{\begin{array}{l}
\sigma_{x} \\
\sigma_{z} \\
\sigma_{x z}
\end{array}\right\}^{(k)}=\left(\begin{array}{ccc}
\bar{Q}_{11} & \bar{Q}_{13} & 0 \\
\bar{Q}_{13} & \bar{Q}_{33} & 0 \\
0 & 0 & \bar{Q}_{55}
\end{array}\right)^{(k)}\left\{\begin{array}{l}
\varepsilon_{x} \\
\varepsilon_{z} \\
\gamma_{x z}
\end{array}\right\},
$$

where $\bar{Q}_{11}, \bar{Q}_{13}, \bar{Q}_{33}, \bar{Q}_{55}$ are reduced stiffness constants of $k^{\text {th }}$-layer in global coordinates, which are related to $\bar{C}_{i j}$ as follows

$$
\begin{gathered}
\bar{Q}_{11}=\bar{C}_{11}+\frac{\bar{C}_{16}^{2} \bar{C}_{22}-2 \bar{C}_{12} \bar{C}_{16} \bar{C}_{26}+\bar{C}_{12}^{2} \bar{C}_{66}}{\bar{C}_{26}^{2}-\bar{C}_{22} \bar{C}_{66}}, \\
\bar{C} Q_{13}=\bar{C}_{13}+\frac{\bar{C}_{16} \bar{C}_{22} \bar{C}_{36}+\bar{C}_{12} \bar{C}_{23} \bar{C}_{66}-\bar{C}_{16} \bar{C}_{23} \bar{C}_{26}-\bar{C}_{12} \bar{C}_{26} \bar{C}_{36}}{\bar{C}_{26}^{2}-\bar{C}_{22} \bar{C}_{66}}, \\
\bar{Q}_{33}=\bar{C}_{33}+\frac{\bar{C}_{36}^{2} \bar{C}_{22}-2 \bar{C}_{23} \bar{C}_{26} \bar{C}_{36}+\bar{C}_{23}^{2} \bar{C}_{66}}{\bar{C}_{26}^{2}-\bar{C}_{22} \bar{C}_{66}}, \\
\bar{Q}_{55}=\bar{C}_{55}-\frac{\bar{C}_{45}^{2}}{\bar{C}_{44}} .
\end{gathered}
$$

It is noted that the displacement field defined in Eq. (1) meets the traction-free boundary conditions of the transverse shear stresss on the top and bottom surfaces of the beam (see Eqs. (6), (3c) and (4b)). Moreover, if the transverse normal stress and higher-order terms of transverse displacements are omitted $\left(\sigma_{z}=0, w_{1}=w_{2}=0\right)$, the strain and stress relation of HOBT is recovered as

$$
\left\{\begin{array}{l}
\sigma_{x} \\
\sigma_{x z}
\end{array}\right\}^{(k)}=\left(\begin{array}{cc}
\overline{\bar{Q}}_{11} & 0 \\
0 & \overline{\bar{Q}}_{55}
\end{array}\right)^{(k)}\left\{\begin{array}{l}
\varepsilon_{x} \\
\gamma_{x z}
\end{array}\right\},
$$

where $\overline{\bar{Q}}_{11}=\bar{Q}_{11}-\frac{\bar{Q}_{13}^{2}}{\bar{Q}_{33}}, \overline{\bar{Q}}_{55}=\bar{Q}_{55}$.

\subsection{Variational formulation}

The total potential energy $\Pi$ of the beam is composed of the strain energy $U$ and work done by external force $V$. The strain energy $U$ is given by

$$
U=\frac{1}{2} \int_{V}\left(\sigma_{x} \varepsilon_{x}+\sigma_{z} \varepsilon_{z}+\sigma_{x z} \gamma_{x z}\right) \mathrm{d} V=\frac{1}{2} \int_{V}\left(\bar{Q}_{11} \varepsilon_{x}^{2}+\bar{Q}_{33} \varepsilon_{z}^{2}+2 \bar{Q}_{13} \varepsilon_{x} \varepsilon_{z}+\bar{Q}_{55} \gamma_{x z}^{2}\right) \mathrm{d} V .
$$

The work done $V$ by transverse load $q$ applied on bottom surface is given by

$$
V=-\int_{0}^{L} q\left(w_{0}-\frac{h}{2} w_{1}+\frac{h^{2}}{4} w_{2}\right) b \mathrm{~d} x .
$$


The total energy of the beam is finally obtained as follows

$$
\Pi=U+V=\frac{1}{2} \int_{V}\left(\bar{Q}_{11} \varepsilon_{x}^{2}+\bar{Q}_{33} \varepsilon_{z}^{2}+2 \bar{Q}_{13} \varepsilon_{x} \varepsilon_{z}+\bar{Q}_{55} \gamma_{x z}^{2}\right) \mathrm{d} V-\int_{0}^{L} q\left(w_{0}-\frac{h}{2} w_{1}+\frac{h^{2}}{4} w_{2}\right) b \mathrm{~d} x .
$$

Substituting Eqs. (3) and Eqs. (4) into Eq. (11), the total energy of the beam becomes

$$
\begin{aligned}
\Pi= & \frac{1}{2} \int_{0}^{L}\left[A_{11}\left(u_{0, x}\right)^{2}+\left(2 B_{11}-\frac{8}{3 h^{2}} E_{11}\right) u_{0, x} u_{1, x}-\frac{8}{3 h^{2}} E_{11} u_{0, x} w_{0, x x}-D_{11} u_{0, x} w_{1, x x}\right. \\
& +2 A_{13} u_{0, x} w_{1}+4 B_{13} u_{0, x} w_{2}-\frac{2}{3} E_{11} u_{0, x} w_{2, x x}+\left(D_{11}+\frac{16}{9 h^{4}} H_{11}-\frac{8}{3 h^{2}} F_{11}\right)\left(u_{1, x}\right)^{2} \\
& +\left(A_{55}-\frac{8}{h^{2}} B_{55}+\frac{16}{h^{4}} D_{55}\right) u_{1}^{2}+\left(\frac{32}{9 h^{4}} H_{11}-\frac{8}{3 h^{2}} F_{11}\right) u_{1, x} w_{0, x x} \\
& +2\left(A_{55}-\frac{8}{h^{2}} B_{55}+\frac{16}{h^{4}} D_{55}\right) u_{1} w_{0, x}+\left(\frac{4}{3 h^{2}} G_{11}-E_{11}\right) u_{1, x} w_{1, x x} \\
& +\left(2 B_{13}-\frac{8}{3 h^{2}} E_{13}\right) u_{1, x} w_{1}+\left(\frac{8}{9 h^{2}} H_{11}-\frac{2}{3} F_{11}\right) u_{1, x} w_{2, x x} \\
& +\left(4 D_{13}-\frac{16}{3 h^{2}} F_{13}\right) u_{1, x} w_{2}+\frac{16}{9 h^{4}} H_{11}\left(w_{0, x x}\right)^{2}+\left(A_{55}-\frac{8}{h^{2}} B_{55}+\frac{16}{h^{4}} D_{55}\right)\left(w_{0, x}\right)^{2} \\
& +\frac{4}{3 h^{2}} G_{11} w_{0, x x} w_{1, x x}-\frac{8}{3 h^{2}} E_{13} w_{0, x x} w_{1}+\frac{8}{9 h^{2}} H_{11} w_{0, x x} w_{2, x x}-\frac{16}{3 h^{2}} F_{13} w_{0, x x} w_{2} \\
& +\frac{1}{4} F_{11}\left(w_{1, x x}\right)^{2}-D_{13} w_{1, x x} w_{1}+A_{33} w_{1}^{2}+\frac{1}{3} G_{11} w_{1, x x} w_{2, x x}-2 E_{13} w_{1, x x} w_{2} \\
& \left.-\frac{2}{3} E_{13} w_{2, x x} w_{1}+4 B_{33} w_{1} w_{2}+\frac{1}{9} H_{11}\left(w_{2, x x}\right)^{2}-\frac{4}{3} F_{13} w_{2, x x} w_{2}+4 D_{33} w_{2}^{2}\right] \mathrm{d} x \\
& -\int_{0}^{L} q\left(w_{0}-\frac{h}{2} w_{1}+\frac{h^{2}}{4} w_{2}\right) b \mathrm{~d} x,
\end{aligned}
$$

where the stiffness coefficients of the beam are determined as follows

$$
\begin{gathered}
\left(A_{11}, B_{11}, D_{11}, E_{11}, F_{11}, G_{11}, H_{11}\right)=\sum_{k=1}^{n} \int_{z_{k}}^{z_{k+1}} \bar{Q}_{11}\left(1, z, z^{2}, z^{3}, z^{4}, z^{5}, z^{6}\right) b \mathrm{~d} z, \\
\left(A_{13}, B_{13}, D_{13}, E_{13}, F_{13}\right)=\sum_{k=1}^{n} \int_{z_{k}}^{z_{k+1}} \bar{Q}_{13}\left(1, z, z^{2}, z^{3}, z^{4}\right) b \mathrm{~d} z, \\
\left(A_{33}, B_{33}, D_{33}\right)=\sum_{k=1}^{n} \int_{z_{k}}^{z_{k+1}} \bar{Q}_{33}\left(1, z, z^{2}\right) b \mathrm{~d} z
\end{gathered}
$$




$$
\left(A_{55}, B_{55}, D_{55}\right)=\sum_{k=1}^{n} \int_{z_{k}}^{z_{k+1}} \bar{Q}_{55}\left(1, z^{2}, z^{4}\right) b \mathrm{~d} z .
$$

Based on the Ritz method, the displacements in Eq. (1) are approximated in the following forms

$$
\begin{gathered}
\left\{u_{0}(x), u_{1}(x)\right\}=\sum_{r=1}^{R} N_{r}^{u}(x)\left\{u_{0 r}, u_{1 r}\right\}, \\
\left\{w_{0}(x), w_{1}(x), w_{2}(x)\right\}=\sum_{r=1}^{R} N_{r}^{w}(x)\left\{w_{0 r}, w_{1 r}, w_{2 r}\right\},
\end{gathered}
$$

where $u_{0 r}, u_{1 r}, w_{0 r}, w_{1 r}, w_{2 r}$ are unknown values to be determined; $N_{r}^{u}(x)$ and $N_{r}^{w}(x)$ are the shape functions which are proposed for simply-supported (S-S), clamped-clamped $(\mathrm{C}-\mathrm{C})$ and clamped-free (C-F) boundary conditions (BC) as follows

$$
\begin{aligned}
& \text { S - S }: N_{r}^{u}(x)=\cos \frac{r \pi x}{L}, N_{r}^{w}(x)=\sin \frac{r \pi x}{L} m, \\
& \text { C - F }: N_{r}^{u}(x)=\sin \frac{(2 r-1) \pi x}{2 L}, N_{r}^{w}(x)=1-\cos \frac{(2 r-1) \pi x}{2 L} m, \\
& \text { C - C }: N_{r}^{u}(x)=\sin \frac{2 r \pi x}{L}, N_{r}^{w}(x)=1-\cos \frac{2 r \pi x}{L} .
\end{aligned}
$$

Table 1. Kinematic boundary conditions of beams

\begin{tabular}{ccc}
\hline BCs & Position & Value \\
\hline S-S & $x=0, x=L$ & \\
C-F & $x=0$ & $u_{0}=0, u_{1}=0, w_{0}=0, w_{1}=0, w_{1}=0, w_{2}=0$ \\
& $x=L$ & \\
C-C & $x=0, x=L$ & $u_{0}=0, w_{1}=0, w_{0}=0, w_{1}=0, w_{2}=0, w_{0, x}=0, w_{1, x}=0, w_{2, x}=0$ \\
\hline
\end{tabular}

It is noted that the approximate functions in Eq. (15) satisfy the BCs given in Tab. 1. The governing equations can be obtained by substituting Eq. (14) into (12), and then using Lagrange's equations

$$
\frac{\partial \Pi}{\partial q_{r}}=0,
$$

with $q_{r}$ representing the values of $\left(u_{0 r}, u_{1 r}, w_{0 r}, w_{1 r}, w_{2 r}\right)$, that leads to

$$
\left[\begin{array}{ccccc}
\mathbf{K}^{11} & \mathbf{K}^{12} & \mathbf{K}^{13} & \mathbf{K}^{14} & \mathbf{K}^{15} \\
{ }^{T} \mathbf{K}^{12} & \mathbf{K}^{22} & \mathbf{K}^{23} & \mathbf{K}^{24} & \mathbf{K}^{25} \\
{ }^{T} \mathbf{K}^{13} & { }^{T} \mathbf{K}^{23} & \mathbf{K}^{33} & \mathbf{K}^{34} & \mathbf{K}^{35} \\
{ }^{T} \mathbf{K}^{14} & { }^{T} \mathbf{K}^{24} & { }^{T} \mathbf{K}^{34} & \mathbf{K}^{44} & \mathbf{K}^{45} \\
{ }^{T} \mathbf{K}^{15} & { }^{T} \mathbf{K}^{25} & { }^{T} \mathbf{K}^{35} & { }^{T} \mathbf{K}^{45} & \mathbf{K}^{55}
\end{array}\right]\left\{\begin{array}{l}
\mathbf{u}_{\mathbf{0}} \\
\mathbf{u}_{\mathbf{1}} \\
\mathbf{w}_{\mathbf{0}} \\
\mathbf{w}_{\mathbf{1}} \\
\mathbf{w}_{\mathbf{2}}
\end{array}\right\}=\left\{\begin{array}{l}
\mathbf{0} \\
\mathbf{0} \\
\mathbf{F}_{\mathbf{0}} \\
\mathbf{F}_{\mathbf{1}} \\
\mathbf{F}_{\mathbf{2}}
\end{array}\right\}
$$


where the components of stiffness matrix $\mathbf{K}$ and load vector $\mathbf{F}$ are given by

$$
\begin{aligned}
& K_{r s}^{11}=A_{11} \int_{0}^{L} N_{r, x}^{u} N_{s, x}^{u} \mathrm{~d} x, \quad K_{r s}^{12}=\left(B_{11}-\frac{4}{3 h^{2}} E_{11}\right) \int_{0}^{L} N_{r, x}^{u} N_{s, x}^{u} \mathrm{~d} x, \quad K_{r s}^{13}=-\frac{4}{3 h^{2}} E_{11} \int_{0}^{L} N_{r, x}^{u} N_{s, x x}^{w} \mathrm{~d} x, \\
& K_{r s}^{14}=-\frac{1}{2} D_{11} \int_{0}^{L} N_{r, x}^{u} N_{s, x x}^{w} \mathrm{~d} x+A_{13} \int_{0}^{L} N_{r, x}^{u} N_{s}^{w} \mathrm{~d} x, \quad K_{r s}^{15}=-\frac{1}{3} E_{11} \int_{0}^{L} N_{r, x}^{u} N_{s, x x}^{w} \mathrm{~d} x+2 B_{13} \int_{0}^{L} N_{r, x}^{u} N_{s}^{w} \mathrm{~d} x, \\
& K_{r s}^{22}=\left(D_{11}-\frac{8}{3 h^{2}} F_{11}+\frac{16}{9 h^{4}} H_{11}\right) \int_{0}^{L} N_{r, x}^{u} N_{s, x}^{u} \mathrm{~d} x+\left(A_{55}-\frac{8}{h^{2}} B_{55}+\frac{16}{h^{4}} D_{55}\right) \int_{0}^{L} N_{r}^{u} N_{s}^{u} \mathrm{~d} x, \\
& K_{r s}^{23}=\left(-\frac{4}{3 h^{2}} F_{11}+\frac{16}{9 h^{4}} H_{11}\right) \int_{0}^{L} N_{r, x}^{u} N_{s, x x}^{w} \mathrm{~d} x+\left(A_{55}-\frac{8}{h^{2}} B_{55}+\frac{16}{h^{4}} D_{55}\right) \int_{0}^{L} N_{r}^{u} N_{s, x}^{w} \mathrm{~d} x, \\
& K_{r s}^{24}=\left(-\frac{1}{2} E_{11}+\frac{2}{3 h^{2}} G_{11}\right) \int_{0}^{L} N_{r, x}^{u} N_{s, x x}^{w} \mathrm{~d} x+\left(B_{13}-\frac{4}{3 h^{2}} E_{13}\right) \int_{0}^{L} N_{r, x}^{u} N_{s}^{w} \mathrm{~d} x, \\
& K_{r s}^{25}=\left(-\frac{1}{3} F_{11}+\frac{4}{9 h^{2}} H_{11}\right) \int_{0}^{L} N_{r, x}^{u} N_{s, x x}^{w} \mathrm{~d} x+\left(2 D_{13}-\frac{8}{3 h^{2}} F_{13}\right) \int_{0}^{L} N_{r, x}^{u} N_{s}^{w} \mathrm{~d} x, \\
& K_{r s}^{33}=\frac{16}{9 h^{4}} H_{11} \int_{0}^{L} N_{r, x x}^{w} N_{s, x x}^{w} \mathrm{~d} x+\left(A_{55}-\frac{8}{h^{2}} B_{55}+\frac{16}{h^{4}} D_{55}\right) \int_{0}^{L} N_{r, x}^{w} N_{s, x}^{w} \mathrm{~d} x, \\
& K_{r s}^{34}=\frac{2}{3 h^{2}} H_{11} \int_{0}^{L} N_{r, x x}^{w} N_{s, x x}^{w} \mathrm{~d} x-\frac{4}{3 h^{2}} E_{13} \int_{0}^{L} N_{r, x x}^{w} N_{s}^{w} \mathrm{~d} x, \\
& K_{r s}^{35}=\frac{4}{9 h^{2}} H_{11} \int_{0}^{L} N_{r, x x}^{w} N_{s, x x}^{w} \mathrm{~d} x-\frac{8}{3 h^{2}} F_{13} \int_{0}^{L} N_{r, x x}^{w} N_{s}^{w} \mathrm{~d} x, \\
& K_{r s}^{44}=\frac{1}{4} F_{11} \int_{0}^{L} N_{r, x x}^{w} N_{s, x x}^{w} \mathrm{~d} x-D_{13} \int_{0}^{L} N_{r, x x}^{w} N_{s}^{w} \mathrm{~d} x+A_{33} \int_{0}^{L} N_{r}^{w} N_{s}^{w} \mathrm{~d} x, \\
& K_{r s}^{45}=\frac{1}{6} G_{11} \int_{0}^{L} N_{r, x x}^{w} N_{s, x x}^{w} \mathrm{~d} x-E_{13} \int_{0}^{L} N_{r, x x}^{w} N_{s}^{w} \mathrm{~d} x-\frac{1}{3} E_{13} \int_{0}^{L} N_{r}^{w} N_{s, x x}^{w} \mathrm{~d} x+2 B_{33} \int_{0}^{L} N_{r}^{w} N_{s}^{w} \mathrm{~d} x, \\
& K_{r s}^{55}=\frac{1}{9} H_{11} \int_{0}^{L} N_{r, x x}^{w} N_{s, x x}^{w} \mathrm{~d} x-\frac{4}{3} F_{13} \int_{0}^{L} N_{r, x x}^{w} N_{s}^{w} \mathrm{~d} x+4 D_{33} \int_{0}^{L} N_{r}^{w} N_{s}^{w} \mathrm{~d} x, \\
& F_{0 r}=\int_{0}^{L} q N_{r}^{w} \mathrm{~d} x, \quad F_{1 r}=-\frac{h}{2} \int_{0}^{L} q N_{r}^{w} \mathrm{~d} x, \quad F_{2 r}=\frac{h^{2}}{4} \int_{0}^{L} q N_{r}^{w} \mathrm{~d} x .
\end{aligned}
$$


Finally, the bending responses of composite beams can be determined by solving Eq. (17).

\section{NUMERICAL RESULTS}

In this section, convergence and verification studies are carried out to demonstrate the accuracy of the present study. For static analysis, the beam is subjected to a uniformly distributed load with density $q$, applied on the surface $z=-h / 2$ in the $z$-direction. Laminates are supposed to have equal thicknesses and made of the same orthotropic materials whose properties are followed: $E_{1} / E_{2}=$ open, $G_{12}=G_{13}=0.5 E_{2}, G_{23}=0.2 E_{2}$ ， $v_{12}=v_{13}=v_{23}=0.25$. For convenience, the following nondimensional terms are used: $\bar{w}=\frac{100 w_{0} E_{2} b h^{3}}{q L^{4}}, \bar{\sigma}_{x}=\frac{b h^{2}}{q L^{2}} \sigma_{x}\left(\frac{L}{2}, \frac{h}{2}\right), \bar{\sigma}_{z}=\frac{b}{q} \sigma_{z}\left(\frac{L}{2}, \frac{h}{2}\right), \bar{\sigma}_{x z}=\frac{b h}{q L} \sigma_{x z}(0,0)$.

In order to verify the convergence of the present series solutions, $\left(0^{0} / 90^{0} / 0^{0}\right)$ and $\left(0^{0} / 90^{0}\right)$ LC beams with $L / h=10, E_{1} / E_{2}=25$ and different BCs subjected to uniformly distributed load are considered. The nondimensional mid-span displacements with respect to the series number $R$ are plotted in Fig. 2. The results show that the solutions from S-S and C-F BCs convergence faster than those from C-C one, and $R=14$ is the convergence point for the displacements for all BCs. Therefore, this number of series terms will be used for the static analysis of LC beams.

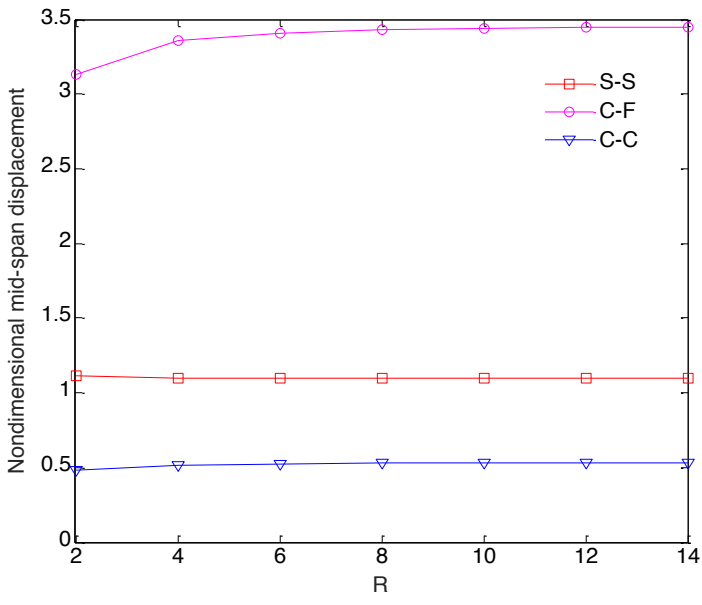

(a) $0^{0} / 90^{0} / 0^{0}$

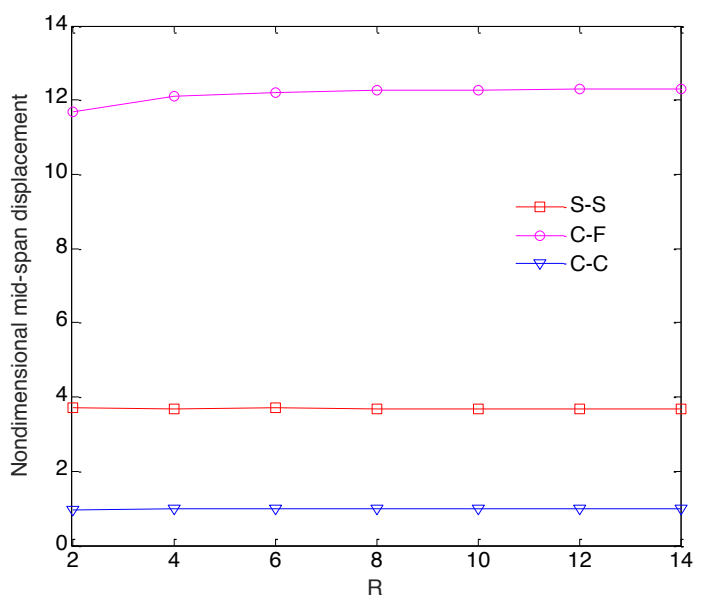

(b) $0^{0} / 90^{\circ}$

Fig. 2. Variation of the nondimensional mid-span displacements of $\left(0^{0} / 90^{0} / 0^{0}\right)$ and $\left(0^{0} / 90^{0}\right) \mathrm{LC}$ beams with respect to the series number $R$ and various $\mathrm{BCs}(L / h=10)$

The next example is to verify the accuracy of the present solutions in predicting the transverse displacements and stresses. Tabs. 2 and 3 present the nondimensional midspan transverse displacements of $\left(0^{0} / 90^{0} / 0^{0}\right)$ and $\left(0^{0} / 90^{\circ}\right)$ LC beams with $E_{1} / E_{2}=25$ subjected to the uniformly distributed load. The solutions obtained from HOBT and 
Table 2. Normalized mid-span displacements of $\left(0^{0} / 90^{0} / 0^{0}\right)$ LC beams under a uniformly distributed load $\left(E_{1} / E_{2}=25\right)$

\begin{tabular}{|c|c|c|c|c|c|c|c|}
\hline \multirow{2}{*}{$\mathrm{BCs}$} & \multirow{2}{*}{ Theory } & \multirow{2}{*}{ Reference } & \multicolumn{5}{|c|}{$L / h$} \\
\hline & & & 3 & 5 & 10 & 20 & 50 \\
\hline \multirow[t]{7}{*}{ S-S } & НOBТ & Present & 5.336 & 2.414 & 1.098 & 0.761 & 0.666 \\
\hline & & Nguyen et al. [41] & & 2.412 & 1.096 & 0.759 & 0.665 \\
\hline & & Murthy et al. [33] & & 2.398 & 1.090 & - & 0.661 \\
\hline & & Khdeir and Reddy [5] & & 2.412 & 1.096 & - & 0.666 \\
\hline & Quasi-3D & Present & 5.283 & 2.405 & 1.097 & 0.761 & 0.666 \\
\hline & & Zenkour [3] & & 2.405 & 1.097 & - & 0.666 \\
\hline & & Mantari and Canales [6] & & & 1.097 & - & - \\
\hline \multirow[t]{6}{*}{$\mathrm{C}-\mathrm{F}$} & HOBT & Present & 13.571 & 6.820 & 3.452 & 2.525 & 2.255 \\
\hline & & Nguyen et al. [41] & & 6.813 & 3.447 & 2.520 & 2.250 \\
\hline & & Murthy et al. [33] & & 6.836 & 3.466 & - & 2.262 \\
\hline & & Khdeir and Reddy [5] & & 6.824 & 3.455 & - & 2.251 \\
\hline & Quasi-3D & Present & 13.605 & 6.821 & 3.450 & 2.524 & 2.254 \\
\hline & & Mantari and Canales [6] & & & 3.459 & - & - \\
\hline \multirow[t]{5}{*}{$\mathrm{C}-\mathrm{C}$} & HOBT & Present & 3.311 & 1.537 & 0.531 & 0.236 & 0.147 \\
\hline & & Nguyen et al. [41] & & 1.536 & 0.531 & 0.236 & 0.147 \\
\hline & & Khdeir and Reddy [5] & & 1.537 & 0.532 & - & 0.147 \\
\hline & Quasi-3D & Present & 3.296 & 1.542 & 0.531 & 0.236 & 0.147 \\
\hline & & Mantari and Canales [6] & & & 0.532 & - & - \\
\hline
\end{tabular}

Table 3. Normalized mid-span displacements of $\left(0^{0} / 90^{0}\right)$ composite beams under a uniformly distributed load $\left(E_{1} / E_{2}=25\right)$

\begin{tabular}{|c|c|c|c|c|c|c|c|}
\hline \multirow{2}{*}{$\mathrm{BC}$} & \multirow{2}{*}{ Theory } & \multirow{2}{*}{ Reference } & \multicolumn{5}{|c|}{$L / h$} \\
\hline & & & 3 & 5 & 10 & 20 & 50 \\
\hline \multirow[t]{8}{*}{ S-S } & HOBT & Present & 7.296 & 4.785 & 3.697 & 3.422 & 3.345 \\
\hline & & Nguyen et al. [41] & & 4.777 & 3.688 & 3.413 & 3.336 \\
\hline & & Murthy et al. [33] & & 4.750 & 3.668 & - & 3.318 \\
\hline & & Khdeir and Reddy [5] & & 4.777 & 3.688 & - & 3.336 \\
\hline & Quasi-3D & Present & 7.158 & 4.764 & 3.694 & 3.421 & 3.344 \\
\hline & & Zenkour [3] & & 4.828 & 3.763 & - & 3.415 \\
\hline & & Mantari and Canales [6] & & & 3.731 & & \\
\hline & & Mantari and Canales [7] & & & 3.732 & - & - \\
\hline \multirow[t]{6}{*}{ C-F } & HOBT & Present & 21.583 & 15.289 & 12.359 & 11.585 & 11.363 \\
\hline & & Nguyen et al. [41] & & 15.260 & 12.330 & 11.556 & 11.335 \\
\hline & & Murthy et al. [33] & & 15.334 & 12.398 & - & 11.392 \\
\hline & & Khdeir and Reddy [5] & & 15.279 & 12.343 & - & 11.337 \\
\hline & Quasi-3D & Present & 21.481 & 15.229 & 12.310 & 11.537 & 11.315 \\
\hline & & Mantari and Canales [6] & & & 12.475 & - & - \\
\hline \multirow[t]{5}{*}{ C-C } & HOBT & Present & 3.764 & 1.922 & 1.006 & 0.754 & 0.680 \\
\hline & & Nguyen et al. [41] & & 1.920 & 1.004 & 0.752 & 0.679 \\
\hline & & Khdeir and Reddy [5] & & 1.922 & 1.005 & - & 0.679 \\
\hline & Quasi-3D & Present & 3.665 & 1.914 & 1.003 & 0.752 & 0.678 \\
\hline & & Mantari and Canales [6] & & & 1.010 & - & - \\
\hline
\end{tabular}


Quasi-3D are calculated at $x=L / 2$ and $z=0$ for different BCs and span-to-height ratios, and compared with those derived from the HOBTs (Nguyen et al. [41], Murthy et al. [33], Khdeir and Reddy [5]) and Quasi-3D (Mantari and Canales [6, 7], Zenkour [3]). It can be seen that the present solutions are in excellent agreement with earlier works for both HOBT and Quasi-3D. Tabs. 2 and 3 also shows that the effects of normal transverse strain on the displacements are effective for thick LC beams $(L / h=3)$. Moreover, Tab. 4 reports the nondimensional axial, transverse shear and normal stresses of $\left(0^{0} / 90^{0} / 0^{0}\right)$ and $\left(0^{0} / 90^{0}\right) \mathrm{LC}$ beams with different ratios of span-to-thickness $L / h=5,10,20$. The results are compared with those derived from Vo and Thai [36] using HOBT and Zenkour [3] using both HOBT and Quasi-3D theory. Good agreements between the models are again found and there are no significant deviations of the present results with and without the effect of transverse normal strain. Figs. 3 and 4 display the distribution of nondimensional shear and axial stresses through the thickness of $\left(0^{0} / 45^{0}\right)$ and $\left(0^{0} / 45^{0} / 0^{0}\right)$ beams. It can be seen that the shear stress meets the traction-free boundary conditions on the top and bottom surfaces of the beam as expected.

Table 4. Normalized stresses of $\left(0^{0} / 90^{0} / 0^{0}\right)$ and $\left(0^{0} / 90^{0}\right)$ composite beams with S-S boundary condition $\left(E_{1} / E_{2}=25\right)$

\begin{tabular}{|c|c|c|c|c|c|c|c|}
\hline \multirow{2}{*}{ Theory } & \multirow{2}{*}{ Reference } & \multicolumn{3}{|c|}{$0^{0} / 90^{0} / 0^{0}$} & \multicolumn{3}{|c|}{$0^{0} / 90^{0}$} \\
\hline & & $L / h=5$ & 10 & 20 & $L / h=5$ & 10 & 20 \\
\hline \multicolumn{8}{|c|}{ Normal axial stress } \\
\hline \multirow{4}{*}{ HOBT } & Present & 1.0689 & 0.8514 & 0.7965 & 0.2362 & 0.2343 & 0.2338 \\
\hline & Nguyen et al. [41] & 1.0696 & 0.8516 & 0.7965 & 0.2362 & 0.2343 & 0.2338 \\
\hline & Zenkour [3] & 1.0669 & 0.8500 & - & 0.2362 & 0.2343 & - \\
\hline & Vo and Thai [36] & 1.0670 & 0.8503 & 0.7961 & 0.2361 & 0.2342 & 0.2337 \\
\hline \multirow[t]{3}{*}{ Quasi-3D } & Present & 1.0743 & 0.8513 & 0.7963 & 0.2383 & 0.2347 & 0.2339 \\
\hline & Zenkour [3] & 1.0732 & 0.8506 & & 0.2276 & 0.2246 & \\
\hline & Mantari and Canales [6] & & 0.8501 & - & - & 0.2227 & - \\
\hline \multicolumn{8}{|c|}{ Shear stress } \\
\hline \multirow[t]{4}{*}{ HOBT } & Present & 0.4050 & 0.4290 & 0.4388 & 0.9174 & 0.9483 & 0.9594 \\
\hline & Nguyen et al. [41] & 0.4050 & 0.4289 & 0.4388 & 0.9174 & 0.9483 & 0.9594 \\
\hline & Zenkour [3] & 0.4057 & 0.4311 & & 0.9211 & 0.9572 & \\
\hline & Vo and Thai [36] & 0.4057 & 0.4311 & 0.4438 & 0.9187 & 0.9484 & 0.9425 \\
\hline \multirow[t]{3}{*}{ Quasi-3D } & Present & 0.4012 & 0.4278 & 0.4387 & 0.9046 & 0.9443 & 0.9587 \\
\hline & Zenkour [3] & 0.4013 & 0.4289 & - & 0.9038 & 0.9469 & - \\
\hline & Mantari and Canales [6] & & & & & 0.9503 & - \\
\hline \multicolumn{8}{|c|}{ Transverse normal stress } \\
\hline \multirow[t]{2}{*}{ Quasi-3D } & Present & 0.1846 & 0.1859 & 0.1846 & 0.3012 & 0.3087 & 0.3091 \\
\hline & Zenkour [3] & 0.1833 & 0.1803 & - & 0.2988 & 0.2982 & - \\
\hline
\end{tabular}

The effects of angle-ply $\theta$ and transverse normal strain on the nondimensional transverse displacement of $\left(0^{0} / \theta^{0}\right)$ and $\left(0^{0} / \theta^{0} / 0^{0}\right)$ LC beams with $L / h=3$ are also plotted in Figs. 5-7 for S-S, C-F and C-C BCs, respectively in which the transverse displacements 

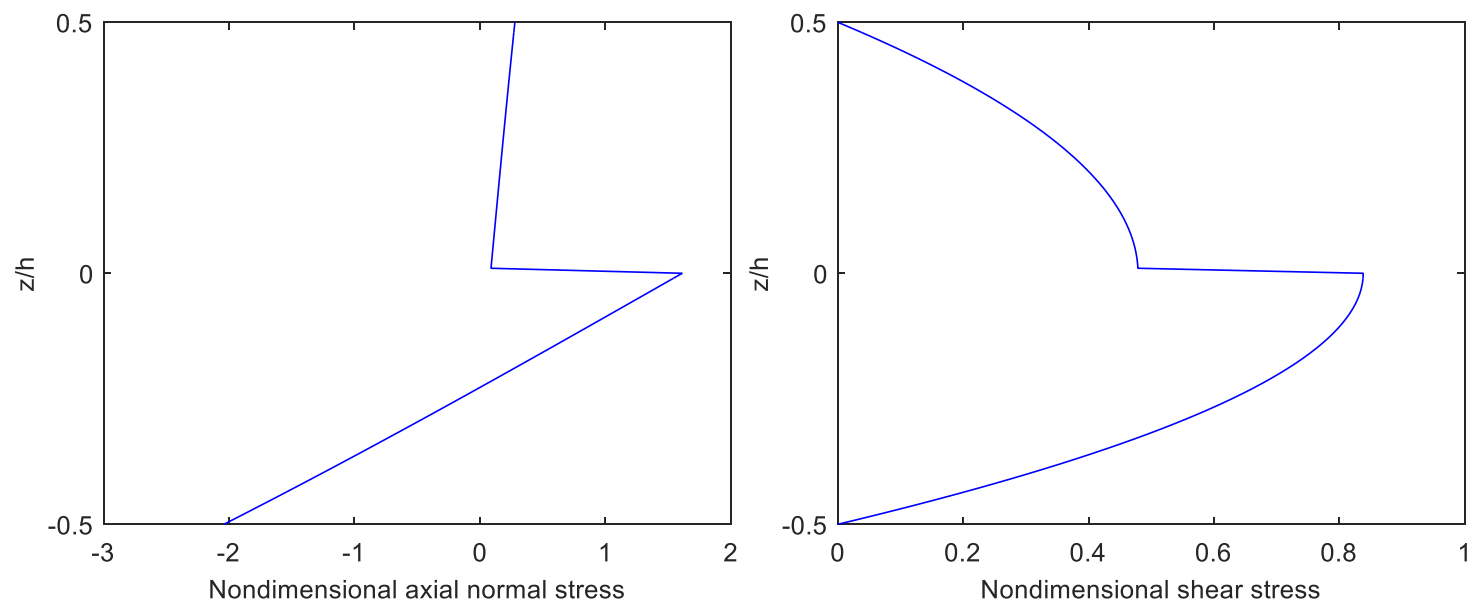

Fig. 3. Distribution of nondimensional stresses through the thickness of $\left(0^{0} / 45^{0}\right)$ S-S BC $(L / h=10)$
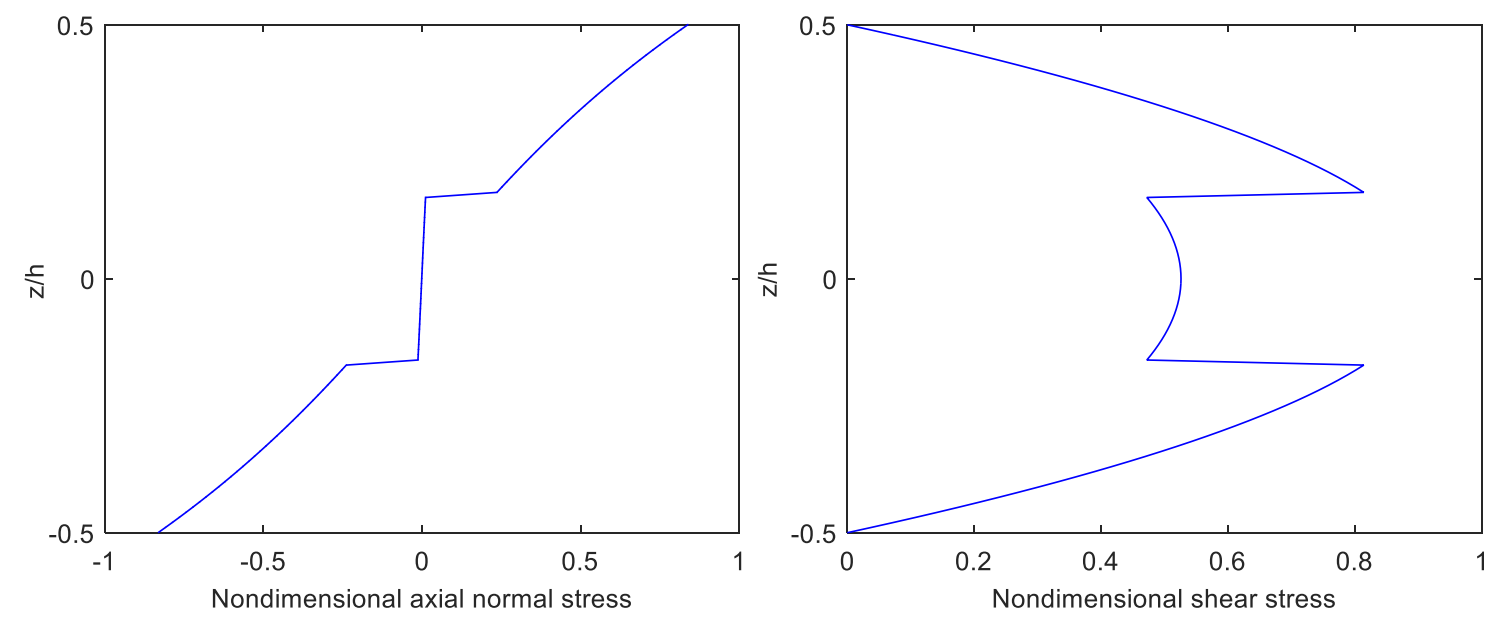

Fig. 4. Distribution of nondimensional stresses through the thickness of $\left(0^{0} / 45^{0} / 0^{0}\right)$ S-S BC $(L / h=10)$

of Quasi-3D model are calculated at $z=0$ and $z=-h / 2$. It is observed that the displacements increase with the increase of angle-ply $\theta$ and there are significant differences between the present results derived from HOBT and from Quasi-3D, especially for asymmetric LC beams and C-C BC. 


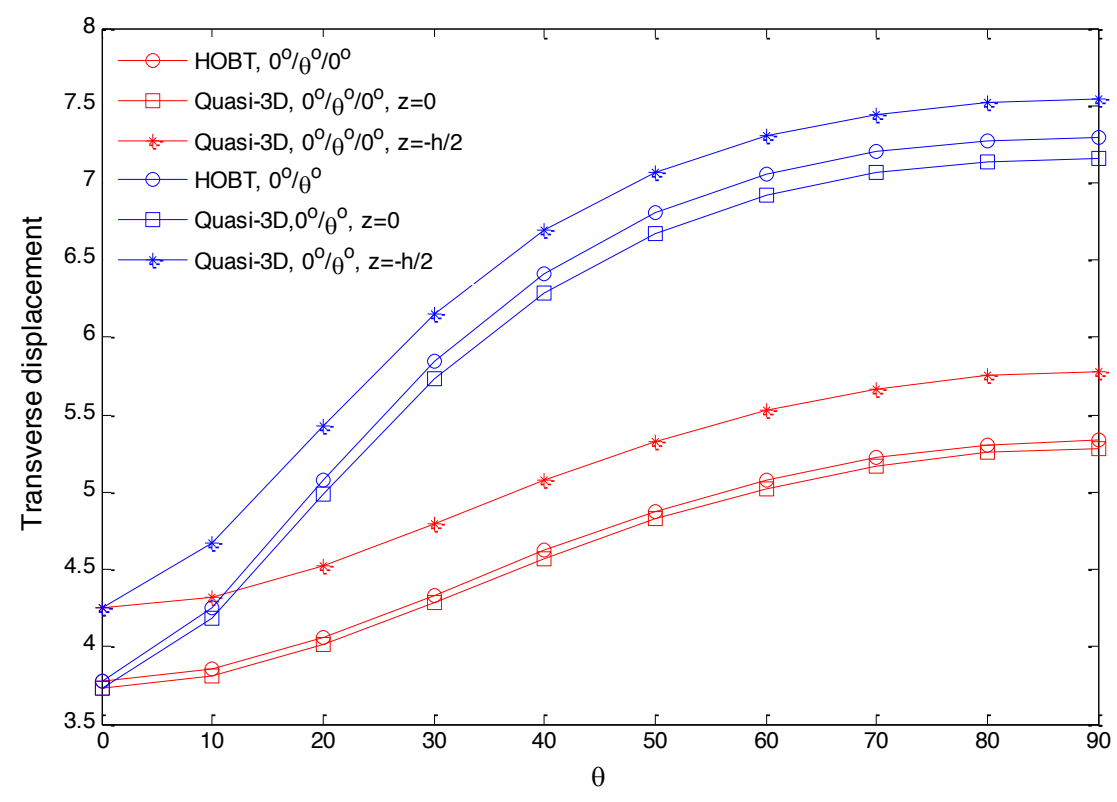

Fig. 5. Nondimensional mid-span transverse displacement with respect to the fiber angle of LC beams with S-S BC $(L / h=3)$

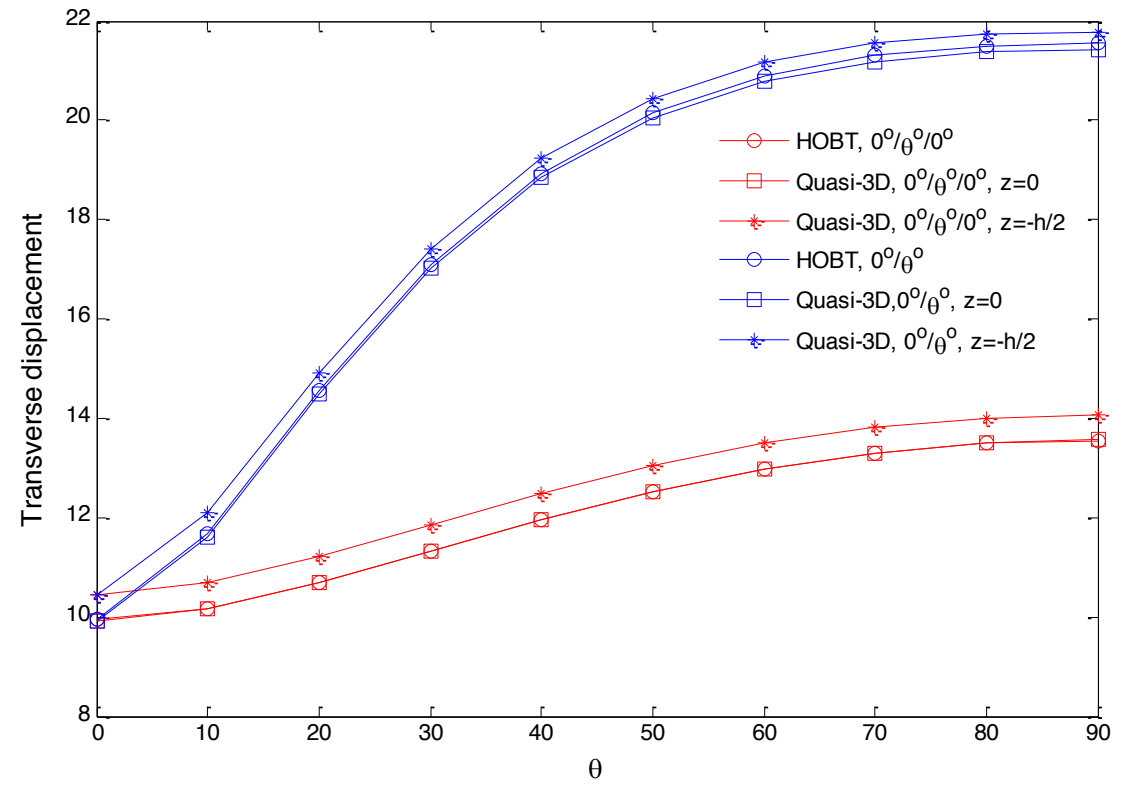

Fig. 6. Nondimensional mid-span transverse displacement with respect to the fiber angle of LC beams with C-F BC $(L / h=3)$ 


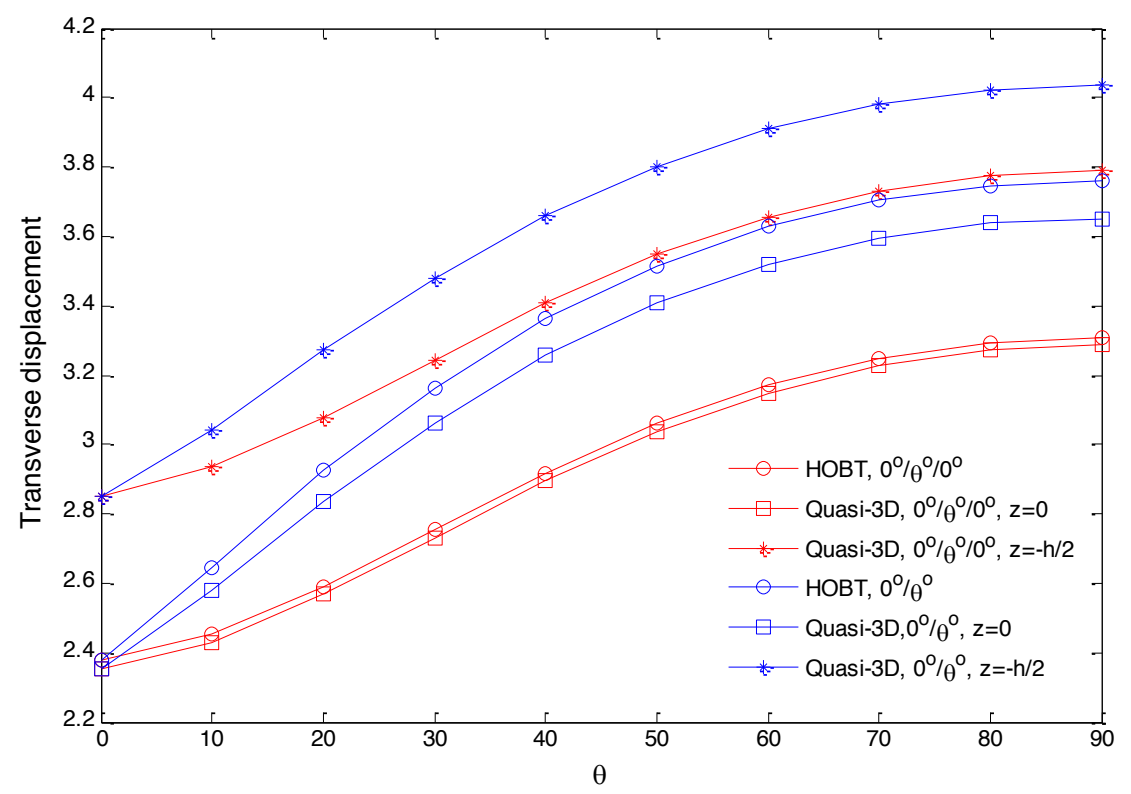

Fig. 7. Nondimensional mid-span transverse displacement with respect to the fiber angle of LC beams with C-C BC $(L / h=3)$

\section{CONCLUSIONS}

Effects of transverse normal strains on the bending behaviours of LC beams are presented in this paper. The displacement field is based on a Quasi-3D theory accounting for a higher-order variation of both axial and transverse displacements. The Ritz method with trigonometric shape functions is used to solve characteristic equations. Numerical results for different $\mathrm{BC}$ s are obtained to compare with previous studies and investigate effects of material anisotropy and angle-ply on the displacements and stresses of LC beams. The obtained numerical results showed that the transverse normal strain effects are significant for un-symmetric and thick beams. The present model is found to be appropriate for static analysis of LC beams.

\section{REFERENCES}

[1] R. P. Shimpi and Y. M. Ghugal. A new layerwise trigonometric shear deformation theory for two-layered cross-ply beams. CRC Press, 61, (9), (2001), pp. 1271-1283. https://doi.org/10.1016/s0266-3538(01)00024-0.

[2] R. P. Shimpi and Y. M. Ghugal. A layerwise trigonometric shear deformation theory for two layered cross-ply laminated beams. Journal of Reinforced Plastics and Composites, 18, (16), (1999), pp. 1516-1543. https://doi.org/10.1177/073168449901801605.

[3] A. M. Zenkour. Transverse shear and normal deformation theory for bending analysis of laminated and sandwich elastic beams. Mechanics of Composite Materials and Structures, 6, (3), (1999), pp. 267-283. https://doi.org/10.1080/107594199305566. 
Trung-Kien Nguyen, Ngoc-Duong Nguyen

[4] K. P. Soldatos and P. Watson. A general theory for the accurate stress analysis of homogeneous and laminated composite beams. International Journal of Solids and Structures, 34, (22), (1997), pp. 2857-2885. https://doi.org/10.1016/s0020-7683(96)00170-9.

[5] A. A. Khdeir and J. N. Reddy. An exact solution for the bending of thin and thick cross-ply laminated beams. Composite Structures, 37, (2), (1997), pp. 195-203. https://doi.org/10.1016/s0263-8223(97)80012-8.

[6] J. L. Mantari and F. G. Canales. Finite element formulation of laminated beams with capability to model the thickness expansion. Composites Part B: Engineering, 101, (2016), pp. 107-115. https://doi.org/10.1016/j.compositesb.2016.06.080.

[7] J. L. Mantari and F. G. Canales. A unified quasi-3D HSDT for the bending analysis of laminated beams. Aerospace Science and Technology, 54, (2016), pp. 267-275. https://doi.org/10.1016/j.ast.2016.04.026.

[8] U. Icardi. A three-dimensional zig-zag theory for analysis of thick laminated beams. Composite Structures, 52, (1), (2001), pp. 123-135. https://doi.org/10.1016/s0263-8223(00)00189-6.

[9] U. Icardi. Higher-order zig-zag model for analysis of thick composite beams with inclusion of transverse normal stress and sublaminates approximations. Composites Part B: Engineering, 32, (4), (2001), pp. 343-354. https://doi.org/10.1016/s1359-8368(01)00016-6.

[10] U. Icardi. Applications of zig-zag theories to sandwich beams. Mechanics of Advanced Materials and Structures, 10, (1), (2003), pp. 77-97. https://doi.org/10.1080/15376490306737.

[11] E. Carrera and G. Giunta. Refined beam theories based on a unified formulation. International Journal of Applied Mechanics, 2, (01), (2010), pp. 117-143. https://doi.org/10.1142/s1758825110000500.

[12] A. Catapano, G. Giunta, S. Belouettar, and E. Carrera. Static analysis of laminated beams via a unified formulation. Composite Structures, 94, (1), (2011), pp. 75-83. https://doi.org/10.1016/j.compstruct.2011.07.015.

[13] A. S. Sayyad and Y. M. Ghugal. Bending, buckling and free vibration of laminated composite and sandwich beams: A critical review of literature. Composite Structures, 171, (2017), pp. 486504. https://doi.org/10.1016/j.compstruct.2017.03.053.

[14] J. Bernoulli. Curvatura laminae elasticae. Acta Eruditorum, 1694, (13), (1964), pp. 262-276.

[15] S. P. Timoshenko. On the correction for shear of the differential equation for transverse vibrations of prismatic bars. The London, Edinburgh, and Dublin Philosophical Magazine and Journal of Science, 41, (245), (1921), pp. 744-746.

[16] S. P. Timoshenko. On the transverse vibrations of bars of uniform cross-section. The London, Edinburgh, and Dublin Philosophical Magazine and Journal of Science, 43, (253), (1922), pp. 125131. https://doi.org/10.1080/14786442208633855.

[17] K. Chandrashekhara, K. Krishnamurthy, and S. Roy. Free vibration of composite beams including rotary inertia and shear deformation. Composite Structures, 14, (4), (1990), pp. 269 279. https://doi.org/10.1016/0263-8223(90)90010-c.

[18] N. T. Khiem and D. T. Hung. A closed-form solution for free vibration of multiple cracked Timoshenko beam and application. Vietnam Journal of Mechanics, 39, (4), (2017), pp. 315-328. https://doi.org/10.15625/0866-7136/9641.

[19] M. Levinson. A new rectangular beam theory. Journal of Sound and Vibration, 74, (1), (1981), pp. 81-87. https://doi.org/10.1016/0022-460x(81)90493-4.

[20] A. V. Krishna Murty. Toward a consistent beam theory. AIAA Journal, 22, (6), (1984), pp. 811816. https://doi.org/10.2514/3.8685.

[21] J. N. Reddy. A simple higher-order theory for laminated composite plates. Journal of Applied Mechanics, 51, (4), (1984), pp. 745-752. https://doi.org/10.1115/1.3167719. 
[22] Y. M. Ghugal and R. P. Shimpi. A trigonometric shear deformation theory for flexure and free vibration of isotropic thick beams. In Structural Engineering Convention, SEC-2000, IIT Bombay, India, (2000), pp. 255-263.

[23] A. S. Sayyad and Y. M. Ghugal. A unified shear deformation theory for the bending of isotropic, functionally graded, laminated and sandwich beams and plates. International Journal of Applied Mechanics, 9, (01), (2017). https://doi.org/10.1142/s1758825117500077.

[24] T. T. Thom and N. D. Kien. Free vibration analysis of 2-D FGM beams in thermal environment based on a new third-order shear deformation theory. Vietnam Journal of Mechanics, 40, (2), (2018), pp. 121-140. https://doi.org/10.15625/0866-7136/10503.

[25] H. Matsunaga. Vibration and buckling of multilayered composite beams according to higher order deformation theories. Journal of Sound and Vibration, 246, (1), (2001), pp. 47-62. https://doi.org/10.1006/jsvi.2000.3627.

[26] W. Q. Chen, C. F. Lv, and Z. G. Bian. Free vibration analysis of generally laminated beams via state-space-based differential quadrature. Composite Structures, 63, (3-4), (2004), pp. 417-425. https://doi.org/10.1016/s0263-8223(03)00190-9.

[27] J. Li, Q. Huo, X. Li, X. Kong, and W. Wu. Vibration analyses of laminated composite beams using refined higher-order shear deformation theory. International Journal of Mechanics and Materials in Design, 10, (1), (2014), pp. 43-52.

[28] A. S. Ghugal and S. Y. M. Effect of transverse shear and transverse normal strain on bending analysis of cross-ply laminated beams. International Journal of Applied Mathematics and Mechanics, 7, (12), (2011), pp. 85-118.

[29] K. Chandrashekhara and K. M. Bangera. Free vibration of composite beams using a refined shear flexible beam element. Computers \& Structures, 43, (4), (1992), pp. 719-727. https://doi.org/10.1016/0045-7949(92)90514-z.

[30] S. R. Marur and T. Kant. Free vibration analysis of fiber reinforced composite beams using higher order theories and finite element modelling. Journal of Sound and Vibration, 194, (3), (1996), pp. 337-351. https://doi.org/10.1006/jsvi.1996.0362.

[31] M. Karama, B. A. Harb, S. Mistou, and S. Caperaa. Bending, buckling and free vibration of laminated composite with a transverse shear stress continuity model. Composites Part B: Engineering, 29, (3), (1998), pp. 223-234. https://doi.org/10.1016/s1359-8368(97)00024-3.

[32] G. Shi and K. Y. Lam. Finite element vibration analysis of composite beams based on higher-order beam theory. Journal of Sound and Vibration, 219, (4), (1999), pp. 707-721. https://doi.org/10.1006/jsvi.1998.1903.

[33] M. V. V. S. Murthy, D. R. Mahapatra, K. Badarinarayana, and S. Gopalakrishnan. A refined higher order finite element for asymmetric composite beams. Composite Structures, 67, (1), (2005), pp. 27-35. https://doi.org/10.1016/j.compstruct.2004.01.005.

[34] P. Vidal and O. Polit. A family of sinus finite elements for the analysis of rectangular laminated beams. Composite Structures, 84, (1), (2008), pp. 56-72. https://doi.org/10.1016/j.compstruct.2007.06.009.

[35] L. Jun and H. Hongxing. Free vibration analyses of axially loaded laminated composite beams based on higher-order shear deformation theory. Meccanica, 46, (6), (2011), pp. 1299 1317. https://doi.org/10.1007/s11012-010-9388-7.

[36] T. P. Vo and H. T. Thai. Static behavior of composite beams using various refined shear deformation theories. Composite Structures, 94, (8), (2012), pp. 2513-2522. https://doi.org/10.1016/j.compstruct.2012.02.010. 
[37] T. P. Vo and H. T. Thai. Vibration and buckling of composite beams using refined shear deformation theory. International Journal of Mechanical Sciences, 62, (1), (2012), pp. 67-76. https://doi.org/10.1016/j.ijmecsci.2012.06.001.

[38] T. P. Vo, H. T. Thai, T. K. Nguyen, D. Lanc, and A. Karamanli. Flexural analysis of laminated composite and sandwich beams using a four-unknown shear and normal deformation theory. Composite Structures, 176, (2017), pp. 388-397. https://doi.org/10.1016/j.compstruct.2017.05.041.

[39] M. Aydogdu. Vibration analysis of cross-ply laminated beams with general boundary conditions by Ritz method. International Journal of Mechanical Sciences, 47, (11), (2005), pp. 17401755. https://doi.org/10.1016/j.ijmecsci.2005.06.010.

[40] J. L. Mantari and F. G. Canales. Free vibration and buckling of laminated beams via hybrid Ritz solution for various penalized boundary conditions. Composite Structures, 152, (2016), pp. 306-315. https://doi.org/10.1016/j.compstruct.2016.05.037.

[41] T. K. Nguyen, N. D. Nguyen, T. P. Vo, and H. T. Thai. Trigonometric-series solution for analysis of laminated composite beams. Composite Structures, 160, (2017), pp. 142-151. https://doi.org/10.1016/j.compstruct.2016.10.033.

[42] J. L. Mantari and J. Yarasca. A simple and accurate generalized shear deformation theory for beams. Composite Structures, 134, (2015), pp. 593-601. https://doi.org/10.1016/j.compstruct.2015.08.073.

[43] J. N. Reddy. Mechanics of laminated composite plates: theory and analysis. CRC press, (1997). 